\title{
EFFECTS OF TRAINING VERSUS SHORT EXERCISE SESSION ON HOMOCYSTEINE LEVELS IN WOMEN WITH DIFFERENT BODY MASS*
}

empirical paper

( ) University School of Physical Education in Wroclaw

DOI: https://doi.org/10.5114/hm.2018.74634

\section{EUGENIA MURAWSKA-CIALOWICZ ${ }^{1}$, JOLANTA ZUWALA-JAGIELLO ${ }^{2}$}

${ }^{1}$ Division of Biochemistry, Physiology and Biochemistry Department

University School of Physical Education, Wroclaw, Poland

${ }^{2}$ Department of Pharmaceutical Biochemistry, Medical University, Wroclaw, Poland

\section{ABSTRACT}

Purpose. Homocysteine is a non-protein amino acid and elevated blood levels are often caused by inappropriate lifestyles, leading to atherosclerosis and cardiovascular diseases. The aim of this study was to determine the levels of homocysteine after a 9-month training program.

Methods. The group studied consisted of obese and overweight women, as well as women with normal body mass. During the training program, control examinations were carried out four times and the following parameters were analyzed: homocysteine blood levels, body mass, BMI, a single 10-minute exercise at a workload of $100 \mathrm{~W}$ and the $\mathrm{VO}_{2}$ max measured using the Astrand-Ryhming method.

Results. The highest homocysteine levels were found in obese women and the lowest in lean women. Higher levels were observed in older women (aged over 50 years) compared to younger women (aged below 50 years). The differences were clearly visible in obese women. Homocysteine levels decreased after the 9-month training program. A single exercise performed every three months during the training program resulted in an increase in homocysteine levels or no changes.

Conclusions. Higher homocysteine levels in the blood after a single exercise are likely caused by faster metabolism of this amino acid. Exercise of moderate intensity leads to a decrease in homocysteine levels in the blood, especially in obese women. Regular physical activity should therefore be recommended not only to prevent and treat obesity but, most importantly, atherosclerosis. Key words: homocysteine, exercise, physical training, women, obesity, overweight

\section{Introduction}

Homocysteine (HC) is a non-protein, highly reactive sulfur-containing amino acid which is vital in methionine metabolism. It is metabolized by methionine remethylation, in the pathway known as the 'active methyl pathway.' This leads to the formation of methyl groups used in the synthesis of different com-

\footnotetext{
* The paper is a modified reprint and a part of the monograph published only in Polish language and titled "The influence of health training on changes of selected adipose tissue hormones and homocysteine levels in women of different body mass" Study and Monographs 104, 2012, Wroclaw University School of Physical Education Publisher.
}

pounds, such as neurotransmitters, phospholipids, hormones, nucleic acids and polyamines. Homocysteine has been recognized as an independent, non-lipid risk factor for atherosclerosis.

HC was discovered by du Vigneaud in 1932, but not until the beginning of the 1960s the first article was published on its pathological significance in patients with homocystinuria [1]. In 1969, a link was noticed between homocysteine levels and thrombosis and embolus formation. McCully, the author of this finding, later developed a theory called 'the homocysteine theory of atherosclerosis' [2]. In 1986, a relationship was found between homocysteine levels and coronary artery disease, and 2 years later a link was found between homocysteine levels and myocardial

Correspondence address: Eugenia Murawska-Cialowicz, Division of Biochemistry, Physiology and Biochemistry Department, Faculty of Physical Education, University School of Physical Education, Wroclaw, Poland,

e-mail: eugenia.murawska-cialowicz@awf.wroc.pl

Received: December 27, 2017

Accepted for publication: March 14, 2018

Citation: Murawska-Cialowicz E, Zuwala-Jagiello J. Effects of training versus short exercise session on homocysteine levels in women with different body mass. Hum Mov. 2018;19(2):18-30; doi: https://doi.org/10.5114/hm.2018.74634. 
infarction [3]. The relation between HC and stroke, the third most common cause of death, has also been shown [4]. However, only recently has there been an increase in homocysteine research in the context of high morbidity and mortality due to cardiovascular diseases caused mostly by an unhealthy lifestyle.

Homocysteine metabolism and synthesis results from complex biochemical pathways such as remethylation, demethylation and transsulfuration. Remethylation is a process leading to methionine being recreated by a methyl group being attached to methylenetetrahydrofolate (MTHF). This process occurs in all tissues, and cofactors - vitamin $\mathrm{B}_{12}$ and folic acid - are necessary for this. This is the dominant direction of the reaction when methionine supply is low. Methionine demethylation leads to the formation of homocysteine via the formation of important indirect metabolites: S-adenosyl methionine (SAM) and S-adenosylhomocysteine (SAH). SAH is hydrolyzed to homocysteine and adenosine. SAM and SAH levels determine the direction of the reaction - homocysteine synthesis or catabolism. Transsulfuration is another important pathway which takes place when there is an excess supply of methionine from the diet. This occurs mainly in the kidneys and liver and partly in the intestines and pancreas. Here, HC is condensed with serine and is irreversibly converted to cysteine, then excreted from the body with urine. Vitamin $\mathrm{B}_{6}$ as a cofactor is necessary for these reactions [5-7].

All three directions of methionine/homocysteine conversions are regulated by enzymes whose genetic defects lead to metabolic disorders of both amino acids and result in hyperhomocysteinemia. The severity of the disorder depends on homocysteine levels.

$\mathrm{HC}$ levels in the blood reflect the rate of methionine conversion, the activity of enzymes participating in its conversion, and the number of cofactors - vitamin $\mathrm{B}_{6}$, vitamin $B_{12}$ and folic acid. Low supplies of $B$ vitamins and renal failure may lead to a significant increase in homocysteine levels. Thus, other important factors modulating HC levels in the blood are the diet and physical exercise which changes the rate of HC conversion and vitamin status [7, 8].

Normal HC levels in the blood are $10-12 \mathrm{mmol} / \mathrm{L}$, although this depends on sex, age, health status, lifestyle, hormonal status, renal function and medication. $\mathrm{HC}$ is lower in children than in teenagers or adults. It is lower in women than men of all ages [5].

According to multicenter study results, an increase in homocysteine levels by $1 \mathrm{mmol} / \mathrm{L}$ increases the risk of coronary artery disease by $3-4 \%$ and of stroke by about $6 \%$ [9]. Other data suggest that an increase by
$5 \mathrm{mmol} / \mathrm{L}$ leads to a 1.6-1.8-fold increase in the risk of these diseases [10]. On the other hand, other research has shown that a decrease in HC levels by approximately 25\% diminishes the risk of coronary artery disease by $11-16 \%$, stroke by $19-22 \%$ and deep vein thrombosis by $25 \%$ [9, 10-12]. Elevated homocysteine levels are also linked to lifestyle factors such as smoking, excess coffee consumption, lack of physical exercise and low supply of dietary folic acid [13, 14]. Additionally, Sawaki et al. [15] showed that psychological stress not only influences systolic blood pressure and heart rate, but also increases blood HC levels under standard conditions.

The apparent association between $\mathrm{HC}$ and cardiovascular diseases $[1,4,9]$, and the possibility of regulating $\mathrm{HC}$ synthesis through vitamin $\mathrm{B}_{6}$, vitamin $\mathrm{B}_{12}$ and folic acid supply and regular physical exercise support taking preventive measures [16]. It is also important as elevated HC levels correlate with insulin resistance [17, 18], markers of oxidative stress [19, 20], and inflammatory markers [21], which coexist with obesity and diabetes, and can be reduced through regular physical exercise.

The association between homocysteine and obesity is not well-documented but in light of the above-mentioned data, it seems apparent. Papandreou et al. [22] estimated homocysteine levels in relation to blood pressure and obesity in 524 children. They found out that blood pressure and body mass index (BMI) do not affect HC levels.

While examining 37 obese girls and 19 boys, Gallistl et al. [23] found following the results of a program aiming to reduce body mass, that HC levels are linked more with lean body mass (LBM) reduction than with fat content. Sanlier et al. [24] examined 355 students with different body mass indexes (BMI) and noticed a weak correlation between $\mathrm{HC}$ and body mass and adipose tissue content.

The aim of this study was to examine whether a 9-month training program of moderate intensity lowers HC levels in women, and whether HC levels depend on the subjects' body masses. The additional aim of this study was to determine how homocysteine levels change after a period of single acute physical exercise undertaken every three months during the 9-month training program.

\section{Material and methods}

\section{The studied group}

75 women aged $45.6 \pm 11.3$ years participated in the study. The aim of training was to reduce body mass 
E. Murawska-Cialowicz, J. Zuwala-Jagiello, Homocysteine after training and exercise

and to improve cardiorespiratory fitness. The women taking part in the study had different body masses, therefore they were divided into three groups on the basis of their BMI values: $\mathrm{BMI} \geq 30.0$ obese women $(\mathrm{O})$; $\mathrm{BMI}=25.0-29.9-$ overweight women $(\mathrm{OV})$; $\mathrm{BMI}<25.0$ - lean women with normal body mass $(\mathrm{N})$.

There were a few exclusion criteria such as, diabetes and thyroid diseases, any medications taken by the subjects affecting lipid parameters, tobacco smoking, and irregular participation in control tests. The average age of group $O$ women $(n=25)$ was $46.3 \pm 10.6$ years, the average age of group OV $(n=24)$ was $47.7 \pm 9.9$ years and of group $\mathrm{N}(n=26)$ was $43.2 \pm 9.6$ years.

During the training period, the women were not asked to change their original eating habits. Their diets were assessed quantitatively and qualitatively during the 9 months of training on the basis of their own prepared menus. Before training, the average protein consumption in all groups was at the level of $0.88 \pm$ $0.18 \mathrm{~g} / \mathrm{kg}$ body mass $(0.92 \pm 0.13 \mathrm{~g} / \mathrm{kg}$ after training, n.s.), of fat at the level of $0.86 \pm 0.3 \mathrm{~g} / \mathrm{kg}$ of body mass $(0.81 \pm 0.2 \mathrm{~g} / \mathrm{kg}$ after training, n.s. $)$, of carbohydrates at the level of $2.75 \pm 0.64 \mathrm{~g} / \mathrm{kg}$ of body mass $(2.95 \pm 0.48 \mathrm{~g} / \mathrm{kg}$ after training, n.s. $)$ and of fiber at the level of $17.51 \pm 5.38 \mathrm{~g} /$ day $(21 \pm 3.20 \mathrm{~g} /$ day after training, $p<0.05$ ).

Due to the wide age range of the subjects within the main groups $(\mathrm{O}, \mathrm{OV}, \mathrm{N})$ formed on the basis of their BMI values, each group was further subdivided into groups of older and younger women. Those aged under 49 (32-49 years old) constituted the group of 'young women' and those aged $\geq 50$ (50-63 years old) belonged to the group of 'older women'. The upper age limit was 50 years as this is the average age when menopause appears in women in Poland [25]. As a result, the following groups were formed: obese younger women (OY), obese older (OO); overweight younger (OVY), overweight older (OVO); normal younger (NY) and normal older (NO). All the participants were informed about the aim of the research, test procedures and the hazards involved. They started performing tests only after signing written consent, and the study protocol was approved by the Senate Ethics Committee for Scientific Research of the University School of Physical Education in Wroclaw, Poland.

\section{Training procedures}

Training sessions were organized twice a week for 9 months. Each exercise unit lasted for 60 minutes. Intensity of the training was at $50-66 \% \mathrm{VO}_{2}$ max. This intensity is typical for a conditioned exercise which enables obtaining energy from fat utilization. Training units were characterized by different efforts undertaken by the subjects. During the first training unit, the method of Total Body Condition was used to build up muscle force, muscle endurance and flexibility. In the second unit, Fat Burning and Low Impact methods were applied to shape aerobic capabilities of the body. During training, heart rate was monitored using the Sportest (Polar, Finland).

During the training program, four control tests were carried out. The first one took place before the training started (0-baseline), the following tests occurred during the $3^{\text {rd }}, 6^{\text {th }}$ and $9^{\text {th }}$ month of the training program. Each control test included: an anthropological study, physiological study (single exercise) and biochemical study.

\section{Anthropological studies}

In the anthropological study, body mass and height and body composition were measured, and BMI was calculated. The assessment of body composition parameters was carried out by spectrometry in nearinfrared (Near Infrared Light) using the FUTREX 6100/XL (Futrex Inc., USA).

\section{Physiological studies}

A single exercise consisted in a subject performing a 10-minute test on an Excalibur Sport (LODE) cycloergometer at a workload of $100 \mathrm{~W}$ and a pedaling frequency of 70-80 rpm. During the test, the content of the exhaled air was monitored by a Quark b2 (Cosmed) ergospirometer and respiratory parameters were measured. Among these, the following were recorded: the volume of oxygen consumption $\left(\mathrm{VO}_{2}\right)$, energy expenditure and the metabolic equivalent of task (MET) were calculated. During the test, changes in heart rate (HR) were recorded, and $\mathrm{VO}_{2}$ max was determined using the Astrand-Ryhming method on the basis of steady state HR during exercise.

\section{Biochemical parameters}

Blood samples for biochemical analyses were taken from fasted subjects between 8 and 10a.m. Then the subjects performed an exercise test after which, at the 15th minute of restitution, their blood was taken again. After serum was obtained, it was stored at $-80^{\circ} \mathrm{C}$ until biochemical analysis was carried out.

Homocysteine was assayed using the FPIA method (Fluorescence Polarization Immunoassay), and an AxSYM 
Homocysteine Reagent Pack (Abbott, USA) in an AxSYM analyzer. The reference values for women was between $3.36-12.5 \mathrm{mmol} / \mathrm{L}$.

Vitamin $\mathrm{B}_{12}$ - in its biologically active form holotranscobalamin (cobalamin connected with transcobalamin II) - was assayed using the MEIA method (Microparticle Enzyme Immunoassay), in an AxSYM analyzer, and an AxSYM Active- $\mathrm{B}_{12}$ (holotranscobalamin) assay was used (Abbott, USA). The normal range was between 19.1-119.3 pmol/L. Folic acid was also determined by the MEIA method using an AxSYM Folate kit (Abbott, USA). The normal range for this was between $7.2-15.4 \mathrm{ng} / \mathrm{ml}$.

\section{Statistical analyses}

Statistical analysis was carried out using Statistica PL Stat Soft version 10.0 (Cracow, Poland). In all tests, the statistically significant level was $p \leq 0.05$. All values were expressed as means \pm SD. The following tests were used to analyze the results: The Shapiro-Wilk test was used to examine normality of distribution. If a variable was characterized by normal distribution, for further calculations one-way analysis of variance (ANOVA) was applied and was preceded by Levene's test of homogeneity of variance. If the null hypothesis of equal variances was rejected $(p \leq 0.05)$, the Duncan's post-hoc test was used for further analysis. Spearman's rank correlation coefficient was cal- culated to evaluate the statistical dependence of the variables.

\section{Ethical approval}

The research related to human use has been complied with all the relevant national regulations and institutional policies, has followed the tenets of the Declaration of Helsinki, and has been approved by the authors' institutional review board or an equivalent committee.

\section{Informed consent}

Informed consent has been obtained from all individuals included in this study.

\section{Results}

The anthropological, physiological and biochemical parameters measured at the baseline, after three, six and nine months of training are presented in table 1.

After 9 months of training in all groups, homocysteine levels significantly decreased compared to the base values (Figure 1). HC levels in women from group $\mathrm{O}$ were significantly higher than those from group $\mathrm{N}$ in each month of study during the training program. In all groups a significant decrease in homocysteine levels was observed during the $3^{\text {rd }}$ month of training and it did not reduce further during the examinations after this.

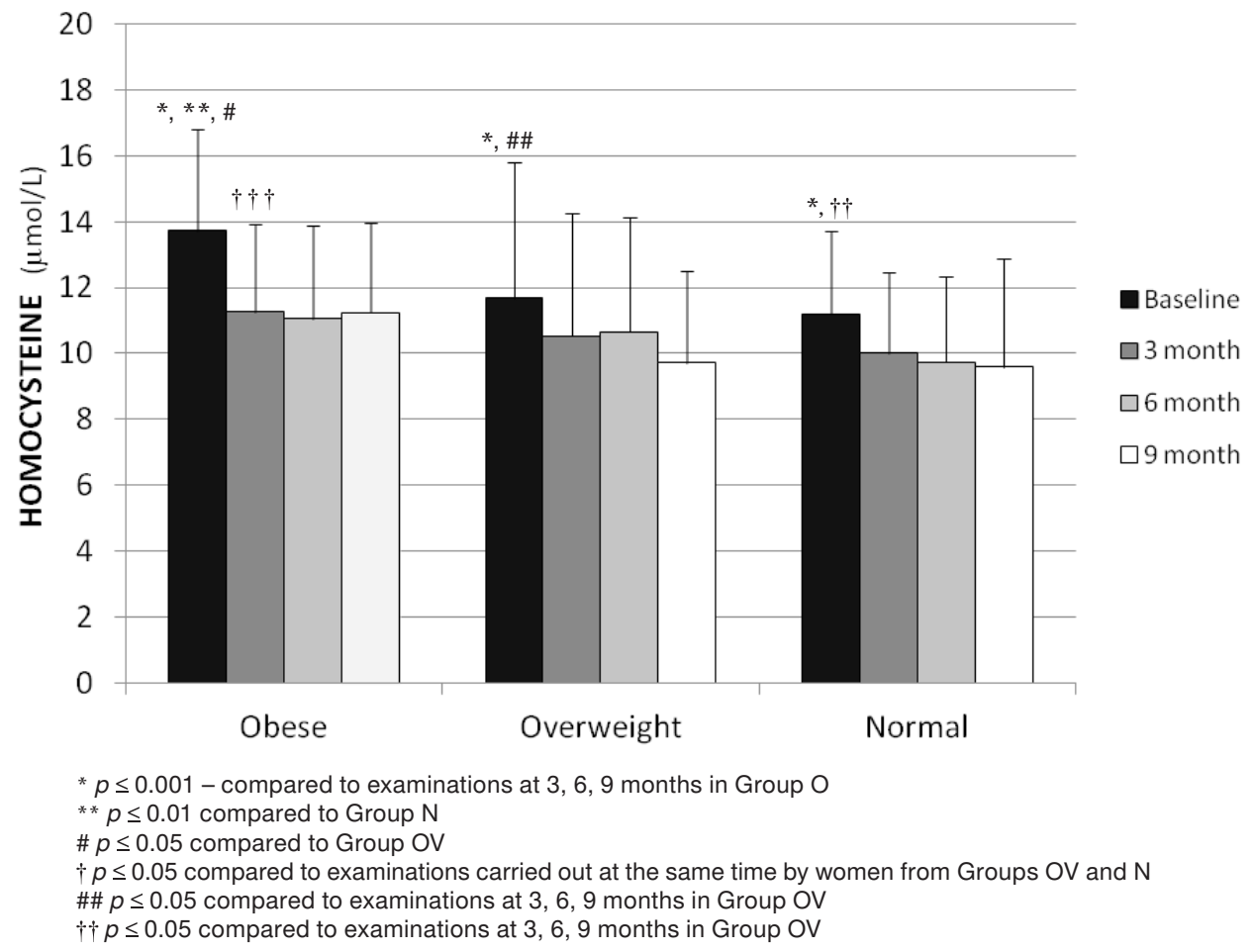

Figure 1. Fasting serum homocysteine at baseline, and at 3, 6 and 9 months post-training for all groups 
E. Murawska-Cialowicz, J. Zuwala-Jagiello, Homocysteine after training and exercise

Table 1. Chosen anthropological, physiological and biochemical parameters.

\begin{tabular}{|c|c|c|c|c|c|}
\hline \multirow{14}{*}{$\begin{array}{l}0 \\
\stackrel{\mathscr{D}}{0} \\
\stackrel{0}{0}\end{array}$} & Parameters & 0 Baseline & 3 month & 6 month & 9 month \\
\hline & Weight $(k g)$ & $86.67 \pm 12.15$ & $83.81 \pm 10.15$ & $79.97 \pm 7.08^{*}$ & $76.47 \pm 6.36^{*}$ \\
\hline & $\operatorname{BMI}\left(k g / m^{2}\right)$ & $32.67 \pm 2.43$ & $31.59 \pm 2.81^{*}$ & $30.83 \pm 2.44^{*}$ & $29.54 \pm 2.17^{*}$ \\
\hline & FAT $(k g)$ & $35.82 \pm 7.07$ & $34.30 \pm 6.49^{*}$ & $32.60 \pm 5.06^{*}$ & $29.53 \pm 4.44^{*}$ \\
\hline & LBM $(k g)$ & $49.31 \pm 4.77$ & $49.20 \pm 6.51$ & $47.59 \pm 4.07^{*}$ & $47.58 \pm 4.36^{*}$ \\
\hline & Cholesterol $(m g / d l)$ & $261.30 \pm 34.91$ & $212.71 \pm 34.27$ & $195.44 \pm 26.94^{*}$ & $210.13 \pm 33.32$ \\
\hline & Triglyceride $(m g / d l)$ & $135.23 \pm 37.83$ & $139.07 \pm 45.21$ & $104.78 \pm 51.33$ & $128.13 \pm 30.76$ \\
\hline & Vit. $B_{12}(\mathrm{pmol} / \mathrm{l})$ before & $59.38 \pm 8.64$ & $56.85 \pm 15.43$ & $73.85 \pm 9.91^{*}$ & $72.75 \pm 9.75^{*}$ \\
\hline & after & $66.73 \pm 12.60^{\dagger}$ & $60.90 \pm 16.32$ & $75.76 \pm 9.22$ & $75.70 \pm 11.99$ \\
\hline & Folic acid $(n g / m l)$ before & $6.80 \pm 4.25$ & $7.81 \pm 5.62$ & $9.60 \pm 4.23^{*}$ & $8.85 \pm 3.25^{*}$ \\
\hline & after & $8.45 \pm 3.60 \dagger$ & $9.81 \pm 4.52 \dagger$ & $10.76 \pm 3.86 \dagger$ & $11.92 \pm 4.52^{\dagger}$ \\
\hline & $\mathrm{VO}_{2 \max }(\mathrm{ml} / \mathrm{kg} / \mathrm{min})$ & $20.87 \pm 5.79$ & $23.63 \pm 5.28^{*}$ & $26.01 \pm 5.65^{*}$ & $30.23 \pm 5.59^{*}$ \\
\hline & MET $(\mathrm{ml} / \mathrm{kg} / \mathrm{min})$ & $6.51 \pm 0.47$ & $6.93 \pm 1.06$ & $5.74 \pm 0.75$ & $5.78 \pm 0.63$ \\
\hline & BPs $(m m H g)$ & $127.79 \pm 15.15$ & $126.82 \pm 14.37$ & $131.43 \pm 14.92$ & $127.50 \pm 10.61$ \\
\hline \multirow{13}{*}{$\begin{array}{l}\vec{z} \\
\frac{\overrightarrow{0}}{00} \\
0 \\
0 \\
0 \\
0 \\
0\end{array}$} & Weight $(k g)$ & $71.79 \pm 6.12$ & $70.23 \pm 5.61$ & $69.83 \pm 5.01$ & $68.10 \pm 5.13^{*}$ \\
\hline & $\operatorname{BMI}\left(k g / m^{2}\right)$ & $26.98 \pm 1.46$ & $26.97 \pm 1.29$ & $25.75 \pm 1.68^{*}$ & $24.46 \pm 2.67^{*}$ \\
\hline & FAT $(k g)$ & $25.59 \pm 4.53$ & $24.79 \pm 2.79$ & $25.18 \pm 3.64$ & $25.49 \pm 5.25$ \\
\hline & $\operatorname{LBM}(k g)$ & $46.36 \pm 4.40$ & $45.47 \pm 4.42$ & $45.95 \pm 4.72$ & $45.63 \pm 4.13$ \\
\hline & Cholesterol $(m g / d l)$ & $206.75 \pm 37.66$ & $217.79 \pm 33.51^{*}$ & $216.08 \pm 36.89$ & $204.80 \pm 32.69$ \\
\hline & Triglyceride $(m g / d l)$ & $129.54 \pm 49.79$ & $115.24 \pm 24.60^{*}$ & $109.38 \pm 31.98^{*}$ & $120.07 \pm 37.74^{*}$ \\
\hline & Vit. $\mathrm{B}_{12}(\mathrm{pmol} / \mathrm{l})$ before & $53.00 \pm 11.02$ & $63.16 \pm 16.81$ & $65.16 \pm 16.98$ & $68.32 \pm 13.25$ \\
\hline & after & $59.28 \pm 13.25^{\dagger}$ & $65.93 \pm 13.24$ & $65.93 \pm 19.14$ & $71.59 \pm 13.50^{\dagger}$ \\
\hline & Folic acid $(\mathrm{ng} / \mathrm{ml})$ before & $9.11 \pm 4.21$ & $11.73 \pm 4.50$ & $12.15 \pm 3.70^{*}$ & $11.83 \pm 5.50^{*}$ \\
\hline & after & $9.29 \pm 3.40$ & $13.08 \pm 3.70^{\dagger}$ & $12.97 \pm 4.20$ & $13.33 \pm 4.60 \dagger$ \\
\hline & $\mathrm{VO}_{2 \max }(\mathrm{ml} / \mathrm{kg} / \mathrm{min})$ & $25.01 \pm 4.96$ & $27.06 \pm 6.38$ & $31.04 \pm 8.72^{*}$ & $29.13 \pm 5.86^{*}$ \\
\hline & $\operatorname{MET}(\mathrm{ml} / \mathrm{kg} / \mathrm{min})$ & $6.69 \pm 0.94$ & $6.69 \pm 1.18$ & $6.70 \pm 0.54$ & $6.01 \pm 0.97$ \\
\hline & $\mathrm{BPs}(\mathrm{mmHg})$ & $127.10 \pm 11.89$ & $123.25 \pm 15.24^{*}$ & $123.64 \pm 15.67$ & $122.50 \pm 10.69$ \\
\hline \multirow{13}{*}{ 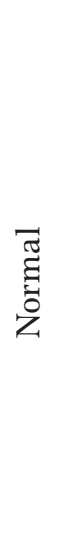 } & Weight $(k g)$ & $60.608 \pm 5.36$ & $62.18 \pm 4.01$ & $61.86 \pm 4.13$ & $59.67 \pm 5.67$ \\
\hline & $\operatorname{BMI}\left(k g / m^{2}\right)$ & $22.68 \pm 1.78$ & $23.08 \pm 1.83$ & $22.58 \pm 1.86$ & $22.35 \pm 1.85$ \\
\hline & FAT $(k g)$ & $17.84 \pm 3.38$ & $18.84 \pm 3.00$ & $18.60 \pm 3.46$ & $17.80 \pm 3.80$ \\
\hline & LBM $(k g)$ & $43.05 \pm 3.81$ & $43.50 \pm 3.04$ & $43.71 \pm 2.31$ & $42.61 \pm 32.31$ \\
\hline & Cholesterol $(m g / d l)$ & $191.50 \pm 46.02$ & $191.00 \pm 37.59$ & $211.00 \pm 46.16$ & $196.00 \pm 42.85$ \\
\hline & Triglyceride $(m g / d l)$ & $84.50 \pm 41.60$ & $90.00 \pm 31.63^{*}$ & $95.00 \pm 29.58^{*}$ & $77.00 \pm 34.65^{*}$ \\
\hline & Vit. $B_{12}(\mathrm{pmol} / \mathrm{l})$ before & $61.55 \pm 13.25$ & $59.04 \pm 12.46$ & $66.19 \pm 13.55$ & $74.33 \pm 14.36^{*}$ \\
\hline & after & $66.41 \pm 13.63^{\dagger}$ & $61.81 \pm 15.12$ & $71.12 \pm 13.65^{\dagger}$ & $76.62 \pm 12.60$ \\
\hline & Folic acid $(n g / m l)$ before & $6.25 \pm 4.00$ & $8.67 \pm 5.80^{*}$ & $9.31 \pm 3.60^{*}$ & $8.74 \pm 4.40^{*}$ \\
\hline & after & $7.21 \pm 4.80 \dagger$ & $9.31 \pm 4.40$ & $11.01 \pm 3.30^{\dagger+}$ & $11.82 \pm 4.90^{+\dagger}$ \\
\hline & $\mathrm{VO}_{2 \max }(\mathrm{ml} / \mathrm{kg} / \mathrm{min})$ & $31.80 \pm 7.97$ & $33.32 \pm 8.85^{*}$ & $34.55 \pm 10.82^{*}$ & $37.11 \pm 10.46^{*}$ \\
\hline & $\operatorname{MET}(\mathrm{ml} / \mathrm{kg} / \mathrm{min})$ & $7.22 \pm 0.68$ & $7.97 \pm 1.48$ & $7.20 \pm 0.56$ & $6.44 \pm 1.21$ \\
\hline & BPs $(m m H g)$ & $126.34 \pm 18.51$ & $118.85 \pm 12.43^{*}$ & $120.94 \pm 9.35$ & $121.67 \pm 7.50$ \\
\hline
\end{tabular}

${ }^{*} p \leq 0.05$ compared to values at baseline; ${ }^{\dagger} p \leq 0.05,{ }^{\dagger \dagger} p \leq 0.01$ compared to values before exercise

The 9-month training program resulted in a decrease in homocysteine levels in women from group $\mathrm{O}$ by $18 \%$, in Group OV by $18.5 \%$, and in Group N by $14.3 \%$.

HC levels were higher in older women, aged 50 and over. This was especially noticeable in obese women. This was observed in that group at baseline, during the examination, and after 3, 6 and 9 months (Figure 2).

It was observed that after the single 10- minute exercise, homocysteine levels either increased or were unchanged (Figure 3).
The most significant changes after a 10-minute single exercise were noticed in the group of obese women where homocysteine levels in the blood increased significantly after each test - by $11.8 \%$ during the $1^{\text {st }}$ test (baseline), by $14.4 \%$ in the $2^{\text {nd }}$ test (in the $3^{\text {rd }}$ month), by $16.7 \%$ in the $3^{\text {rd }}$ test (in the $6^{\text {th }}$ month) and by $19.9 \%$ in the $4^{\text {th }}$ test (in the $9^{\text {th }}$ month). In Group OV, a significant increase in homocysteine levels after each test was only noted during the 6th month of training (by $17.2 \%$ ), and in the $9^{\text {th }}$ month (by $13.3 \%$ ). In Group N 


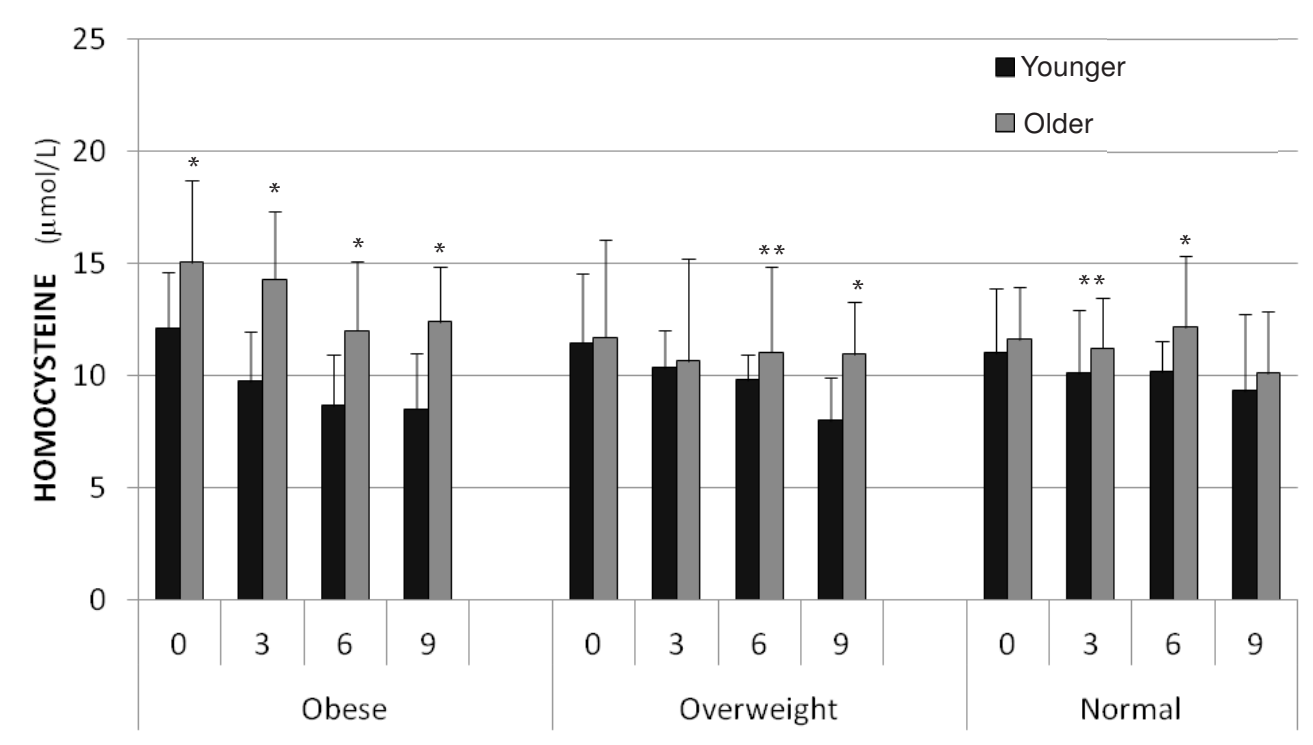

${ }^{*} p \leq 0.001 ; * * 00.05$ compared to younger women

Figure 2. Serum homocysteine in younger and older women at baseline and at 3, 6 and 9 months post-training

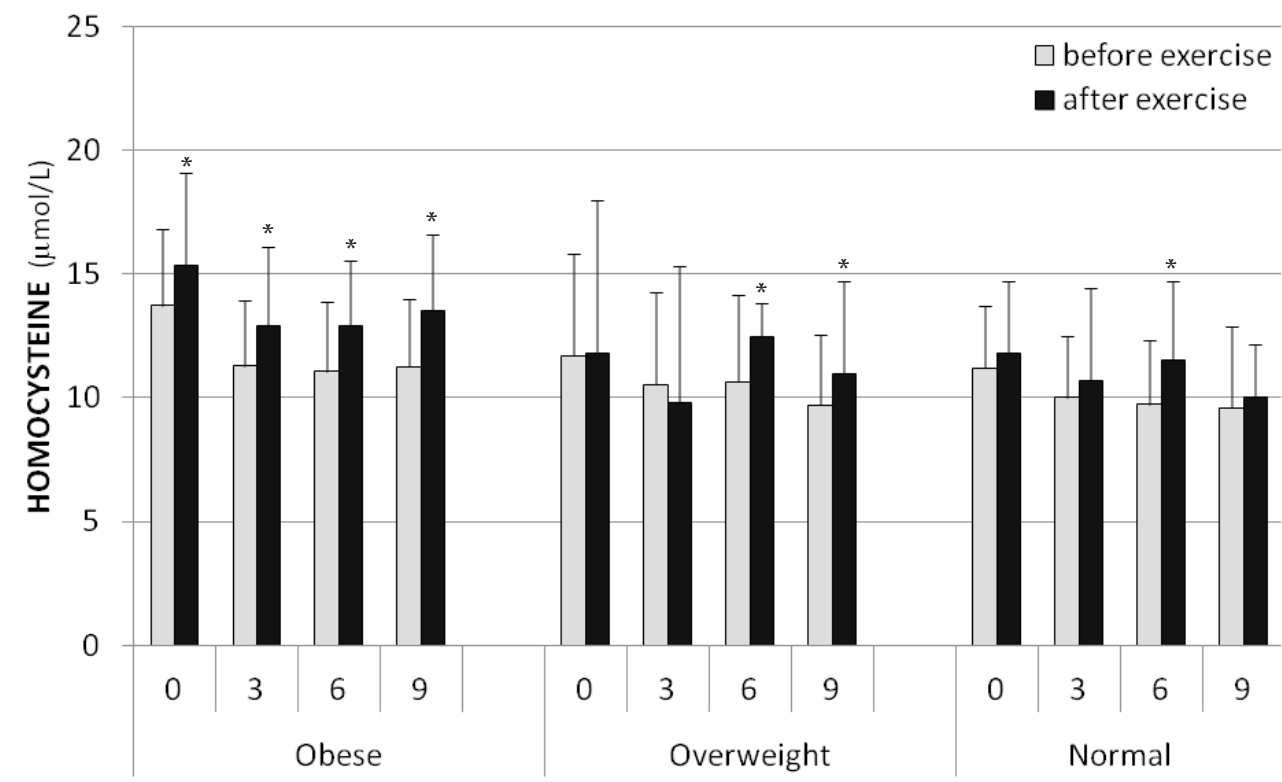

${ }^{*} p \leq 0.05$ compared to values before exercise

Figure 3. Fasting serum homocysteine and after 10 minute exercise at baseline, and at 3, 6 and 9 months post-training

the values of $\mathrm{HC}$ only changed during the $3^{\text {rd }}$ test were an increase by $18.1 \%$.was noted.

An increase in homocysteine levels after a single exercise was most noticeable in older women. In women from Group O, a significant increase in $\mathrm{HC}$ level was only observed in Group OO. The overweight group was also characterized by a significant increase in $\mathrm{HC}$ levels in women from Group OVO, but only in the $3^{\text {rd }}$ and $6^{\text {th }}$ months of training. In the groups of younger obese women and those with normal body mass, there were no changes in $\mathrm{HC}$ after a 10-minute test, however, in the overweight group, a decrease in HC level was noted during the $3^{\text {rd }}$ month and in the $9^{\text {th }}$ month levels increased.
In lean women with a normal body mass, the changes were not as marked as those in overweight and obese women. In the entire study group, a positive correlation between $\mathrm{HC}$ level and BMI was noticed $(r=0.35)$ and a negative correlation with $\mathrm{VO}_{2} \max (r=-0.35)$.

\section{Discussion}

Here we show the lowest fasting HC levels were observed in the group of obese women. Although the mean value of $\mathrm{HC}$ levels noted in this group seems to be within the upper limits of the accepted norm for this method, it is thought that HC has adverse influences on the human body which can be apparent at the level 


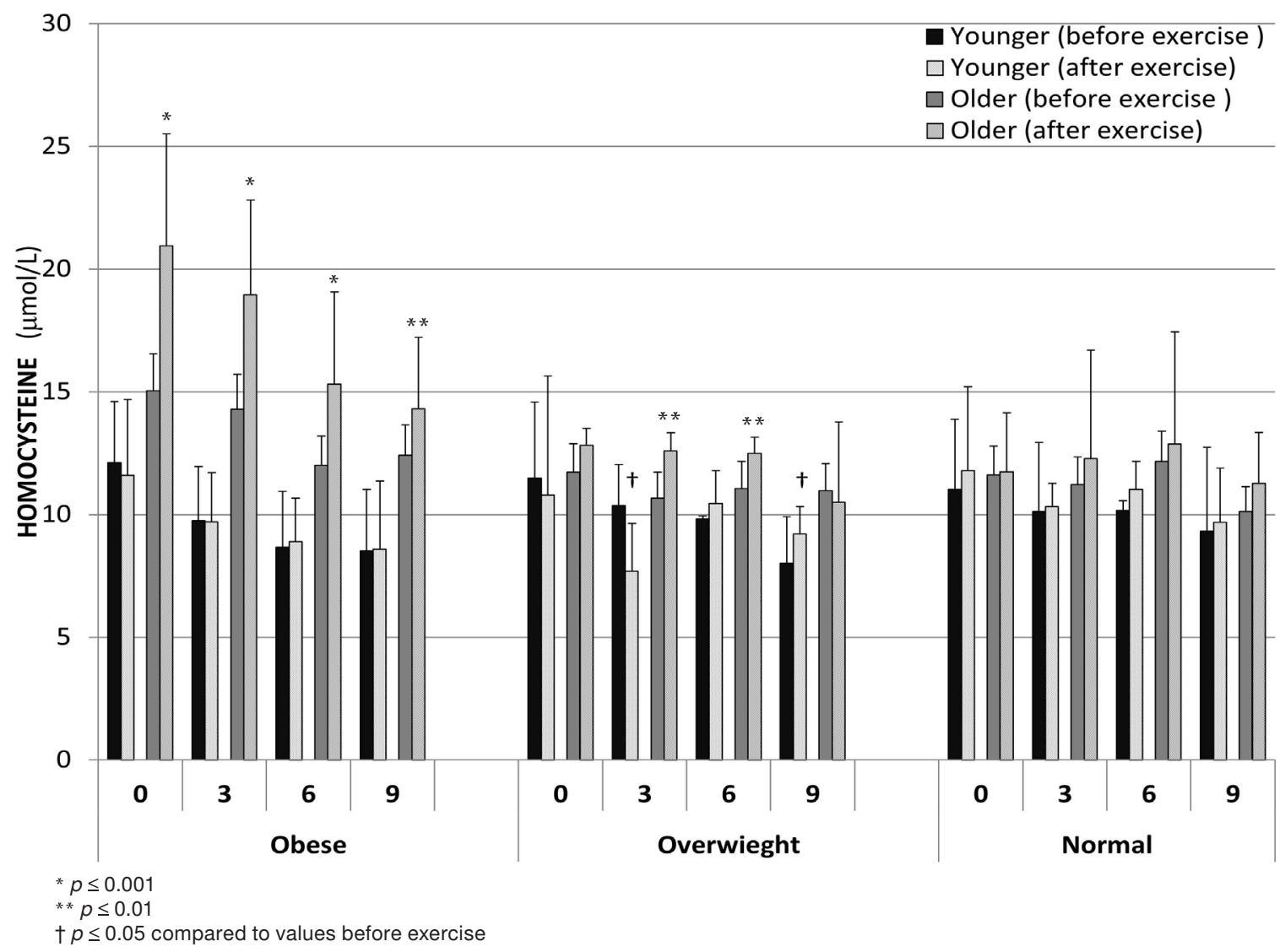

Figure 4. Fasting serum homocysteine and after 10 minute exercise in younger and older women

of $10 \mathrm{mmol} / \mathrm{L}$, which is considered normal [26]. In the whole group of older women, HC levels often exceeded normal values. This was especially apparent in Group O. In overweight women before training, HC levels were a little higher than in lean women. The training program resulted in a decrease in HC levels in all the groups studied. The initial results were evident after three months and throughout the entire training program, HC levels remained low.

Immediately after exertion, homocysteine levels increased in all the groups studied. This was especially noticeable in Group O. However, there were no changes in HC levels in women from Groups OV and N at baseline and after 3 months of training. Our results were similar to those presented by Deminice et al. [27]. It is important to note that an increase in HC levels after a 10-minute exercise was higher in older women than in younger women. This may suggest a faster metabolic reaction in this group caused, for instance by a higher demand for products of homocysteine metabolism, e.g. methyl groups. A greater increase in $\mathrm{HC}$ levels in older women may also show that physical exercise modifies HC levels in the blood. These results are consistent with our own research. Men and women at different levels of physical performance carried out a progressive test and it was found that fasting homocysteine levels and the values of post-exercise changes depended on the level of physical performance [28]. The authors demonstrated unequivocally that there was a negative correlation between homocysteine levels and the quantity of work done. The subjects in the study with the longest sports career had the lowest fasting $\mathrm{HC}$ values and the biggest increase in $\mathrm{HC}$ levels after exertion - by $20 \%$. An increase in homocysteine levels immediately after exertion was also observed by Wright et al. [29] in healthy, physically active men after a 30 -minute run at an intensity of $70 \% \mathrm{HR}_{\text {max }}$, by König et al. [16] in trained triathletes and by Hermann et al. [30] in recreationally trained marathon runners. Their homocysteine levels rose by $64 \%$, while there were no significant changes in athletes after a $120 \mathrm{~km}$ mountain biking race and a $100 \mathrm{~km}$ run. Homocysteine levels correlated negatively with the duration of the run. Therefore, it can be assumed that the most important factors determining changes in HC levels are the duration and intensity of exercise [27]. While assaying homocysteine after a half marathon race in elite and nonelite runners, Benedini et al. [31] also observed an 
increase in HC levels after a run lasting 75-100 min, and the pace of the run provoked an intensity close to the anaerobic threshold. In other studies, Subasi et al. [32] analyzed homocysteine levels after resistance exercise but found no changes.

Ebenbichler et al. [33] observed bodybuilders during different phases of their preparation for competitions and noticed much higher values of HC levels during the muscle mass development phase, helping them reach the conclusion that a higher intake of anabolic steroids during this phase stimulates hyperhomocysteinemia, which intensifies mechanisms leading to greater coagulation promotion in this group of athletes.

Elevated HC levels in obese and overweight women suffering from hypertension were also noticed by Karatela and Sainani [34]. Similarly, the research by Sadeghi et al. [35] shows that homocysteine correlates with BMI, body mass fat and lean body mass.

During physical exercise, significant metabolic changes occur and the degree to which normal homeostasis is disturbed depends on many factors connected with the exercise itself - its type, intensity duration and also on systemic factors, level of physiological adaptation and, linked with this, the tolerance of homeostasis disturbance in response to exercise.

An increase in blood homocysteine levels may be due to intensified activity by several mechanisms. It may be assumed that post-exercise changes are caused by an increased energy demand on the body during exercise as well as its demand for methyl groups whose donor is methionine - the precursor of homocysteine - and an increased protein turnover.

Homocysteine metabolism results from proper functioning of a few cofactors. Amongst these, the most important are folic acid and vitamin $\mathrm{B}_{12}$, participating in remethylation, and vitamin $B_{6}$, which is present in remethylation and transsulfuration. Vitamin deficiency may result in more intensive homocysteine synthesis. Methionine supply in a diet also plays a role. During an increased supply of methionine, the transsulfuration pathway, which leads to the synthesis of cysteine, becomes dominant. When supply is low, remethylation becomes dominant and de novo synthesis of methionine occurs. The main source of methionine in the diet is animal protein, the consumption of which results in an increase in homocysteine levels and is maintained in healthy people up to 24 hours after a meal [36].

Individuals who consume significant amounts of meat have higher homocysteine levels than vegetarians [37]. However, in people with a vegetarian diet with a low supply of methionine and vitamin $\mathrm{B}_{12}$, a shift in the balance of the two metabolic processes in favor of methionine synthesis is possible, thus homocysteine levels can become higher [30]. If the diet is enriched with the $\mathrm{B}$ vitamins, the level of this amino acid may be low [38].

It has also been shown that a low supply of vitamins participating in homocysteine metabolism, in particular folic acid, leads to an increase in blood HC levels [8], therefore vitamin supplements are recommended for people with elevated homocysteine levels. Rousseau et al. [39] and Joubert [40] also claim that of all the vitamins present in homocysteine metabolism, folic acid in particular, fosters a reduction in resting homocysteine levels in individuals who train intensively. Similar conclusions have been reached by other researchers [16, 41, 42].

Hyperhomocysteinemia is such an important health issue that in 1998 the Governments of the USA and Canada mandated that wheat flour was to be enriched with folic acid to a level of $140-150 \mathrm{mg} / 100 \mathrm{~g}$. As a result, the risk of stroke decreased by $8-16 \%$ [5].

In our study, a slight increase in the levels of vita$\min B_{12}$ and folic acid was observed following a single period exercise. Levels of both of these vitamins also increased due to the training applied. Physical exercise may lead to an increase in homocysteine levels during recovery, through its influence on protein catabolism and, at the same time, on methionine catabolism, an increased demand for methyl groups, as well as changes in vitamins $\mathrm{B}_{6}, \mathrm{~B}_{12}$ and folic acid status.

From a study by Venta et al. [43] it may be concluded that immediately after 30-minutes of exercise, there is an increase in homocysteine levels, and also levels of cysteine, vitamin $\mathrm{B}_{12}$ and pyridoxal 5'- phosphate (the most biologically active form of vitamin $\mathrm{B}_{6}$ ). On the other hand, Weiss [44] noted a 33\% decrease in methionine levels in students after a run of moderate intensity following $150 \mathrm{~min}$ of recovery. This demonstrates that during exercise the transsulfuration pathway becomes dominant and leads to an increase in homocysteine levels at the cost of methionine used during exercise. Therefore, in response to physical exercise, elevated levels of vitamin $B_{12}$ and folic acid are observed. As a result of this adaptive reaction, the organism strives to supplement its methionine deficiency, stimulates remethylation and synthesizes the amino acid de novo. This mechanism may also function as a biochemical adaptive reaction when an organism is subjected to regular exercise. As a body's methionine supply is constantly being depleted, there is a decrease in homocysteine levels due to training and $\mathrm{HC}$ being remethylized back into methionine, however only if the supplies of vitamin $B_{12}$ and folic acid are sufficient. 
E. Murawska-Cialowicz, J. Zuwala-Jagiello, Homocysteine after training and exercise

Higher values of vitamin $B_{12}$ and folic acid immediately after exercise were noticed in previous examinations after Wingate and progressive tests [45].

According to Hadj-Saad et al. [46], vitamin $\mathrm{B}_{6}$ levels in the blood increase after 1 hour of an intensive swimming exercise in rats as due to its being shifted from a muscle deposit pool, however, levels decrease after 9-weeks of training [47]. Vitamin $\mathrm{B}_{6}$ is responsible for protein and amino acid metabolism and a cofactor for many enzymes participating in amino acid transformation. During exercise amino acids are used in glucogenesis as a source of energy for muscle work and in the conversion of lactate into glucose. There are other enzymes also involved in processes where pyridoxal 5'-phosphate is a cofactor.

During exercise, vitamin $\mathrm{B}_{6}$ is also used to form glucose 6-phosphate from glycogen breakdown in the muscles and to produce energy [40, 48]. Therefore, insufficient supply of this vitamin in the diet and intensive physical effort may result in HC levels decreasing or remaining unchanged, as suggested by some authors $[30,32,49]$. As vitamin $B_{6}$ is mainly used to provide energy for working muscles, it does not play a significant role in homocysteine metabolism. It is also thought that small doses of vitamin $\mathrm{B}_{6}$ should be used to prevent hypercholesterolemia because when administered in doses of $1.6 \mathrm{mg} /$ day for 12 weeks, it causes a decrease in homocysteine levels [50].

Another reason why homocysteine levels increase after exercise may be associated with increased demand for methyl groups. Homocysteine is a product of S-Adenosyl methionine, which is an important donor of methyl groups used in many transformations such as the synthesis of DNA, RNA, creatine, phosphatidylcholine, adrenaline and carnitine [6, 51-53]. Creatine synthesis amounts for approximately $75 \%$ of daily homocysteine production [40, 54]. When the methyl group is transferred from S-Adenosyl methionine to guanidine acetate, S-Adenosyl homocysteine is formed, along with a particle of creatine which is further converted into phosphocreatine used as an energy source for intensively working muscles. Creatine is converted to creatinine, which is secreted by kidneys. Thus, it can be inferred that long, high-intensity exercise which leads to an increase in creatine levels later used for phosphocreatine synthesis, may contribute to an increase in blood homocysteine levels [55].

Venta et al. [43] claim that significant changes in kidney functioning during exercise are the main cause of elevated levels of thiol amino acids in the blood after intensive physical exercise, rather than metabolic changes.
There seems to be a close relationship between glomerular filtration and homocysteine levels in the blood, which is shown by numerous studies presented by Van Guldener [7]. Other research shows that approximately $20 \%$ of the daily production of S-Adenosyl methionine takes place in the kidneys [52]. All these mechanisms could provide an explanation for an increase in HC levels which were observed in our study after intensive exercise undertaken by the subjects.

Our study also suggests that a 9-month health training program significantly decreased homocysteine levels in the blood, compared to a single exercise of intensity above the anaerobic threshold. Similar observations were noted by other authors who claimed that physically active people have lower levels of homocysteine compared with those who do not train [20, 21, $28,49]$. These observations may demonstrate that regular aerobic training regulates homocysteine metabolism in the blood, which could be used in the prevention and treatment of diseases caused by hypokinesis.

In our research, a significant decrease in $\mathrm{HC} \mathrm{lev-}$ els following training was observed in all groups by the second examination, which was carried out after 3 months of training. There was a decrease of $14.6 \%$ in Group O, by $11.7 \%$ in Group OV and by $10.5 \%$ in Group N, respectively, followed by only a small decrease in further examinations. A 9-month training program resulted in decreased HC levels by $18 \%, 18.5 \%$ and $14.3 \%$, respectively. An improvement in cardiorespiratory fitness accompanied these changes according to the $\mathrm{VO}_{2 \max }$, in each group studied. A negative correlation between homocysteine and $\mathrm{VO}_{2 \max }$ seems to be a clear confirmation of a relationship between physical performance and homocysteine levels. Research by Kuo et al. [56] also observed an inverse correlation between $\mathrm{VO}_{2 \max }$ and homocysteine levels in women. The authors claimed that HC level is a vital indicator of exercise tolerance in women and can be used as an indicator of improvement in cardiovascular fitness from training. Okura et al. [57], and Venta et al. [43], also showed in their research a negative correlation between these parameters.

Lower blood HC levels after training may also be a direct result of the influence of peroxisome proliferator-activated receptor - coactivator (PGC)-1a, on $\mathrm{HC}$ transformation in liver. Li et al. [58] showed that PGC-1a affects the genes of enzymes participating in $\mathrm{HC}$ transformation, and regulates its synthesis and remethylation. The study implies that physical exercise influences expression of PGC-1a in skeletal muscles. PGC-1a is one of the most vital factors regulating a body's energy metabolism [59]. It stimulates mito- 
chondrial biogenesis, regulates fatty acid oxidation [60, 61], participates in blood pressure regulation, stimulates cholesterol homeostasis, regulates inflammatory processes and stimulates the formation of brown adipose tissue (BAT) [62]. During physical exercise the expression of PGC-1a is stimulated mainly by hypoxia, reactive oxygen species (ROS) or mechanical forces.

From our observations it can be concluded that training at intensity below the anaerobic threshold in the women participating in our study, was, in the case of homocysteine, a stimulus for adaptation which was particularly noticeable during the initial phases of the training, and in the later phases only stimulated to maintain the previously achieved HC levels. To induce further decreases in $\mathrm{HC}$ levels, exercise of much higher intensity at or above the anaerobic threshold should be applied (although such an outcome cannot be guaranteed). There was also a decrease in the physiological cost of work analyzed on the basis of steady state HR during each test.

Homocysteine participates in many adverse processes within the blood vessels (oxidative stress, stimulation of blood coagulation processes, endothelial damage, increased platelet adhesion, LDL oxidation and proliferation of vascular smooth muscle cells), but is often an underestimated factor in cardiovascular diseases and osteoporosis [63-67]. Disease risk increases when $\mathrm{HC}$ levels in the blood exceed $10 \mathrm{mmol} / \mathrm{L}[5,68]$. In our research $\mathrm{HC}$ correlated negatively with $\mathrm{VO}_{2 \max }$ but there was also a positive correlation with BMI and cholesterol levels (data not shown). This observation is quite interesting as until now, homocysteine has not been thought to correlate with other risk markers for cardiovascular diseases.

In our study, we found $\mathrm{HC}$ also correlated with body fat percentage and mass in the group of obese women. A correlation with fat content in women was also noticed in our previous research [29]. The elevated homocysteine levels we observed, may be to a large extent a consequence of lowered levels of both vita$\min B_{12}$ and folic acid noted in the group of older women (data not shown). It is well known that levels of both these vitamins decrease with age and is often a cause of anemia or higher blood pressure in elderly people. Lack of both vitamins may also lead to a number of nervous system disorders and, most of all, to atherosclerosis in later life, or even Alzheimer's disease [69]. Due to these factors, both vitamins are used preventatively to lower high blood pressure and, as shown in recent studies, is successfully used in obese people with type 2 diabetes to improve glycemia and insulin sensitivity [70]. According to Li et al. [58] suppression of
PGC-1a in the liver could be used in the future as a preventive measure against hyperglycemia and as well as supplementation with vitamins $\mathrm{B}_{6}$ and $\mathrm{B}_{12}$, could be used as an alternative method of lowering HC levels.

\section{Acknowledgements}

The research was financed by the Ministry of Science and Higher Education with funds from project no. NN 404036738, after obtaining permission from the Senate Ethics Committee for Scientific Research of the University School of Physical Education in Wroclaw, Poland.

\section{Disclosure statement}

No author has any financial interest or received any financial benefit from this research.

\section{Conflict of interest}

The authors state no conflict of interest.

\section{References}

1. Magott M. Homocysteine as a nonlipid factor in the pathogenesis of atherosclerosis [Homocysteina nielipidowym czynnikiem patogenezy miażdżycy, in Polish]. Postępy Hig Med Dosw. 1998;52(3):259-267.

2. McCully KS, Wilson RB.Homocysteine theory of atherosclerosis. Atherosclerosis. 1975;22(2):215-227; doi: 10.1016/0021-9150(75)90004-0.

3. Wichlińska-Lipka M, Nyka WM. The role of homocysteine in pathogenesis of nervous system diseases. [Rola homocysteiny w patogenezie chorób układu nerwowego, in Polish]. Forum Med Rodz. 2009;2:292-297.

4. Banecka-Majkutewicz Z, Gąsecki D, Jakóbkiewicz-Banecka J, Banecki B, Węgrzyn G, Nyka WM. Hyperhomocysteinemia - an important risk factor for stroke [Hiperhomocysteinemia - ważny czynnik ryzyka udaru mózgu, in Polish]. Udar Mózgu. 2005;7:61-65.

5. Hermann W, Hermann M, Obeid R. Hyperhomocysteinaemia: a critical review of old and new aspects. Curr Drug Metab. 2007;8(1):17-31; doi: 10.2174/1389200 07779315008.

6. Mudd SH, Brosnan JT, Brosnan ME, Jacobs RL, Stabler SP, Allen RH, et al. Methyl balance and transmethylation fluxes in humans. Am J Clin Nutr. 2007;85(1): 1925; doi: 10.1093/ajcn/85.1.19.

7. Van Guldener C. Why is homocysteine elevated in renal failure and what can be expected from homocysteine-lowering? Nephrol Dial Transplant. 2006;21(5):1161-1166; doi: 10.1093/ndt/gfl044.

8. De Bree A, Verschuren WM, Blom HJ, Kromhout D. Lifestyle factors and plasma homocysteine concentrations in a general population sample. Am J Epidemiol. 2001;154(2):150-154; doi:10.1093/aje/154.2.150.

9. Homocysteine Studies Collaboration. Homocysteine and risk of ischemic heart disease and stroke. A meta-analy- 
E. Murawska-Cialowicz, J. Zuwala-Jagiello, Homocysteine after training and exercise

sis. JAMA 2002; 288(16):2015-2022; doi:10.1001/jama. 288.16.2015.

10. Prasad K. Homocysteine, a risk factor for cardiovascular disease. Int J Angiol. 1999;8(1),76-86; doi: 10.1007/ BF01616850.

11. Evans RW, Shaten BJ, Hempel JD, Cutler JA, Kuller LH. Homocyst(e)ine and risk of cardiovascular diseases in the multiple risk factor intervention trial. Arterioscler Thromb Vasc Biol. 1997;17(10):1947-1953; doi: 10.1161/ 01.ATV.17.10.1947.

12. Wierzbicki AS. Homocysteine and cardiovascular disease: a review of the evidence. Diab Vasc Dis Res. 2007; 4(2):143-150; doi: 10.3132/dvdr.2007.033.

13. Nurk E, Tell GS, Vollset SE, Nygård O, Refsum H, Nilsen RM, et al. Changes in lifestyle and plasma total homocysteine: The Hordaland Homocysteine Study. Am J ClinNutr. 2004;79(5):812-819; doi: 10.1093/ajcn/79.5.812.

14. Wang X., Qin X., Demirtas H., Li J., Mao G., Huo Y., et al. Efficacy of folic acid supplementation in stroke prevention: a meta-analysis. Lancet. 2007;369(9576):18761882; doi: 10.1016/S0140-6736(07)60854-X.

15. Sawaki A, Ohshige K, Kura N, Tochikuba O. Influence of mental stress on the plasma homocysteine level and blood pressure change in young men. Clin Exp Hypertens. 2008;30(3):233-241; doi: 10.1080/1064196080 2068725.

16. König D, Bissé E, Deibert P, Müller HM, Wieland H, Berg A. Influence of training volume and acute physical exercise on the homocysteine levels in endurance-trained men: interactions with plasma folate and vitamin B12. Ann Nutr Metab. 2003;47(3-4):114-118; doi: 10.1159/ 000070032.

17. Hajer GR, van der Graaf Y, Olijhoek JK, Verhaar MC, Visseren FL, SMART Study Group. Levels of homocysteine are increased in metabolic syndrome patients but are not associated with an increased cardiovascular risk, in contrast to patients without the metabolic syndrome. Heart. 2007;93(2):216-220; doi: 10.1136/ hrt.2006.093971.

18. Rekha S, Patel ML, Pooja G, Pushpalata S, Natu SM, Pradeep Y. Correlation of plasma homocysteine levels with BMI and insulin resistance, amongst obese, overweight and non obese infertile women. Int J Sci Res Pub. 2012;2(5):1-6.

19. Murawska-Ciałowicz E, Januszewska L, Zuwała-Jagiełło J, Milczarska J, Zawadzki M, Paprocka-Borowicz M, Wierzbicka-Damska I. Melatonin decreases homocysteine level in blood of rats. J Physiol Pharmacol. 2008; 59(4):717-729.

20. Vincent HK, Bourgignon C, Vincent KR. Resistance training lowers exercise-induced oxidative stress and homocysteine levels in overweight and obese older adults. Obesity. 2006;14(11):1921-1930; doi: 10.1038/oby.2006. 224.

21. Hübner-Woźniak E, Ochocki P. Effects of training on resting plasma levels of homocysteine and C-reactive protein in competitive male and female wrestlers. Bio- med Hum Kinet 2009;1:42-46; doi: 10.2478/v10101009-0011-0.

22. Papandreou D, Rousso I, Makedou A, Arvanitidou M, Mavromichalis I. Association of blood pressure, obesity and serum homocysteine levels in healthy children. Acta Paediatr. 2007;96(12):1819-1823; doi: 10.1111/ j.1651-2227.2007.00563.x.

23. Gallistl S, Sudi KM, Erwa W, Aigner R, Borkebnstein M. Determinants of homocysteine during weight reduction in obese children and adolescents. Metabolism. 2005;50(10):1220-1223; doi: 10.1053/meta.2001.25646.

24. Sanlier N, Yabanci N. Relationship between body mass index, lipids and homocysteine levels in university students. J Pak Med Assoc. 2007;57(10):491-495.

25. Milewicz A, Jędrzejuk D. Hormonal replacement therapy in diabetes [Hormonalna terapia zastępcza w cukrzycy, in Polish]. Diab Prac. 2004;5(1):41-44.

26. Rechciński T. Hyperhomocysteinemia. Pathomechanisms, diagnosis, treatment [Hiperhomocysteinemia patomechanizmy, diagnostyka, leczenie, in Polish]. Forum Kardiologów. 2001;6:67-69.

27. Deminice R, Ribeiro DF, Frajacomo FTT. The Effects of acute exercise and exercise training on plasma homocysteine: A meta-analysis. PLOS. 2016; 11(3):e0151653; doi: 10.1371/journal.pone.0151653.

28. Murawska-Ciałowicz E., Wierzbicka-Damska I., Kałwa M., Milczarska J., Paprocka-Borowicz M., Januszewska L., Zawadzki M., Pieróg B. Homocysteine, vitamin B12 and folic acid concentration in blood of men and women after endurance exercise up to exhaustion. Polish J Environ Stud. 2006;15(2b):1442-1445.

29. Wright M, Francis K, Cornwell P. Effect of acute exercise on plasma homocysteine. J Sports Med Phys Fitness. 1998;38(3):262-265.

30. Hermann M, Schorr H, Obeid R, Scharhag J, Urhausen A, Kindermann W, et al. Homocysteine increases during endurance exercise. Clin Chem Lab Med. 2003; 41(11):1518-152; doi: 10.1515/CCLM.2003.233.

31. Benedini S, Caimi A, Alberti G, Terruzzi I, Dellerma N, La Torre A, et al. Increase in homocysteine levels after a half- marathon running: a detrimental metabolic effect of sport? Sport Sci Health. 2010;6(1):35-42; doi: doi.org/10.1007/s11332-010-0094-6.

32. Subasi SS, Gelecek N, Özdemir N, Ormen M. Influences of acute resistance and aerobic exercises on plasma homocysteine level and lipid profiles. Turk J Biochem. 2009;34:9-14.

33. Ebenbichler CF, Kaser S, Bodner J, Gander R, Lechleitner M, Herold M, et al. Hyperhomocysteinemia in bodybuilders taking anabolic steroids. Eur J Int Med. 2001;12(1):43-47; doi: 10.1016/S0953-6205(00)00131-X.

34. Karatela RA, Sainani GS. Plasma homocysteine in obese, overweight and normal weight hypertensives and normotensives. Indian Heart J. 2009;61(2):156-159.

35. Sadeghi O, Askari G, Maghsoudi Z, Nasiri M, Khorvash K, Ghiasvand R. Association of general obesity with hyperhomocysteinemia in patients with migraine. Jundis- 
hapur J Chronic Dis Care. 2015, January; 4(1): e26596; doi: $10.5812 /$ jjcdc. 26596.

36. Guttormsen AB, Schneede J, Fiskerstrand T, Ueland PM, Refsum HM. Plasma concentrations of homocysteine and other aminothiol compounds are related to food intake in healthy human subjects. J Nutr. 1994; 124(10): 1934-1941;doi: 10.1093/jn/124.10.1934.

37. Krajcovicova-Kudlackova M, Blazicek P, Kopcova J, Bederova A, Babinska K. Homocysteine levels in vegetarians versus omnivores. Ann Nutr Metab. 2000;44(3): 135-138; doi: 10.1159/000012827.

38. DeRose DJ, Charles-Marcel ZL, Jamison JM, Muscat JE, Braman MA, McLane GD, et al. Vegan diet-based lifestyle program rapidly lowers homocysteine levels. Prev Med.2000;30(3):225-233; doi:10.1006/pmed.1999.0623.

39. Rousseau AS, Robin S, Roussel AM, Ducros V, Margaritis I. Plasma homocysteine is related to folate intake but not training status. Nutr Metab Cardiovasc Dis. 2005;15(2),125-133; doi:10.1016/j.numecd.2005.02.002.

40. Joubert LM. Exercise, nutrition, and homocysteine. Thesis for the degree of Doctor of. Philosophy. Oregon State University; 2008.

41. Refsum H, Smith AD, Ueland PM, Nexo E, Clarke R, McPartlin J, et al. Facts and recommendations about total homocysteine determinations: an expert opinion. Clin Chem. 2004;50(1):3-32; doi: 10.1373/clinchem. 2003.021634.

42. Ueland PM, Hustad S. Homocysteine and folate status in an era of folic acid fortification: balancing benefits, risks, and B-vitamins. Clin Chem. 2008;54(5): 779-781; doi: 10.1373/clinchem.2008.103218.

43. Venta R, Cruz E, Valcarcel G, Terrados N. Plasma vitamins, amino acids, and renal function in postexercise hyperhomocysteinemia. Med Sci Sports Exerc. 2009; 41(8):1646-1652; doi:10.1249/MSS.0b013e31819e02f2.

44. Weiss M. Einflus einer extensiven belastung auf das aminosaure-spektrum und die homocystein-plasmakonzentration. Deutsche Zeitschrift fur Sportmedizin. 1999;50: 152-157.

45. Murawska-Ciałowicz E. The impact of Wingate and progressive tests on homocysteine, vitamin B6, B12 and folic acid levels in athlete's blood. CEJSSM. 2014; 8(4): 5-17.

46. Hadj-Saad F, Lhuissier M, Guilland JC. Effects of acute, submaximal exercise on vitamin B6 metabolism in the rat. Nutr Res. 1995;15(8):1181-1189; doi: 10.1016/02715317(95)00077-V.

47. Hadj-Saad F, Lhuissier M, Guilland JC. Chronic exercise affects vitamin B-6 metabolism but not requirement of growing rats. J Nutr. 1997;127(6):1219-1228; doi: 10.1093/jn/127.6.1219.

48. Manore MM. Effect of physical activity on thiamine, riboflavin, and vitamin B-6 requirements. Am J Clin Nutr. 2000;72(2 Suppl):598S-606S; doi: 10.1093/ajcn/ 72.2.598S.

49. Gaume V, Mougin F, Figard H, Simon-Rigaud ML, N'Guyen UN, Callier J, et al. Physical training decreases total plasma homocysteine and cysteine in middle-aged subjects. Ann Nutr Metab. 2005;49(2):125-131; doi: 10.1159/000085536.

50. McKinley MC, McNulty H, McPartlin J, Strain JJ, Pentieva K, Ward M, et al. Low-dose vitamin B-6 effectively lowers fasting plasma homocysteine in healthy elderly persons who are folate and riboflavin replete. Am J Clin Nutr. 2001;73(4):759-764; doi: 10.1093/ajcn/ 73.4.759..

51. Ulrey CL, Liu L, Andrews LG, Tollefsbol TO. The impact of metabolism on DNA methylation. Hum Mol Genet. 2005; 14 Suppl 1: 139-147; doi:10.1093/hmg/ ddi100.

52. Stead LM, Brosnan JT, Brosnan ME, Vance DE, Jacobs RL. Is it time to reevaluate methyl balance in humans? Am J Clin Nutr. 2006;83(1):5-10; doi: 10.1093/ ajcn/83.1.5.

53. Wilson FA, van den Borne JJGC, Calder GA, O’Kennedy N, Holtrop G, Rees WD, et al. Tissue methionine cycle activity and homocysteine metabolism in female rats: impact of dietary methionine and folate plus choline.AmJPhysiolEndocrinolMetab.2009;296(4):E702E713; doi: 10.1152/ajpendo.90670.2008.

54. Da Silva RP, Nissim I, Brosnan ME, Brosnan JT. Creatine synthesis: hepatic metabolism of guanidinoacetate and creatine in the rat in vitro and in vivo. Am J Physiol Endocrinol Metab. 2009;296(2):E256-E261; doi: 10.1152/ ajpendo.90547.2008.

55. Joubert LM, Manore MM. Exercise, nutrition, and homocysteine. Int J Sport Nutr Exerc Metab. 2006; 16(4): 341-361; doi: 10.1123/ijsnem.16.4.341.

56. Kuo HK, Yen CJ, Bean JF. Levels of homocysteine are inversely associated with cardiovascular fitness in women, but not in men: data from the National Health and Nutrition Examination Survey 1999-2002. J Intern Med.2005;258(4):328-335; doi: 10.1111/j.1365-2796. 2005.01546.x.

57. Okura T, Rankinen T, Gagnon J, Lussier-Cacan S, Davignon J, Leon AS, et al. Effect of regular exercise on homocysteine concentrations: the HERITAGE Famile Study. Eur J Appl Physiol. 2006;98(4),394-401; doi: 10.1007/ s00421-006-0294-6.

58. Li S, Arning E, Liu C, Vitvitsky V, Hernandez C, Banerjee R, et al. Regulation of homocysteine homeostasis through the transcriptional coactivator PGC-1 $\alpha$. Am J Physiol Endocrinol Metab. 2009;296:E543-E548; doi: 10.1152/ajpendo.90719.2008.

59. Liang H, Ward WF. PGC-1 $\alpha$ : a key regulator of energy metabolism. Adv Physiol Edu. 2006;30(4):145-151; doi: 10.1152/advan.00052.2006.

60. Ventura-Clapier R, Garnier A, Veksler V. Transcriptional control of mitochondrial biogenesis: the central role of PGC-1 $\alpha$. Cardiovasc Res. 2008;79(2),208-217; doi: 10.1093/cvr/cvn098.

61. Dinas PC, Lahart IM, Timmons JA, Svensson P-A, Koutedakis Y, Flouris AD, et al. Effects of physical activity on the link between PGC-1a and FNDC5 in muscle, 


\section{HUMAN MOVEMENT}

E. Murawska-Cialowicz, J. Zuwala-Jagiello, Homocysteine after training and exercise

circulating Irisin and UCP1 of white adipocytes in humans: A systematic review. F1000 Res. 2017;6:286; doi: 10.12688/f1000research.11107.2.

62. Cantó C, Auwerx J. PGC-1alpha, SIRT1 and AMPK, an energy sensing network that controls energy expenditure. Curr Opin Lipidol. 2009;20(2):98-105; doi: 10.1097/ MOL.0b013e328328d0a4.

63. Prerost MR. Feldman BF. Herbert WG. Homocysteine, fibrinogen and physical activity in human males with coronary artery disease. Comp Haematol Int. 1999; 9(1):25-30; doi: 10.1007/BF02585518.

64. Rabczynski M, Fiodorenko-Dumas Z, Adamiec R, Paprocka-Borowicz M, Dumas I. Role of anti-HSP 60/65 antibodies in atherogenesis in patients with type 2 diabetes and lower limb ischemia. J Physiol Pharmacol. 2012;63(6):691-696.

65. Kado DM, Bucur A, Selhub J, Rowe JW, Seeman T. Homocysteine levels and decline in physical function: McArthur studies of successful aging. Am J Med. 2002; 113(7): 537-542; doi: 10.1016/S0002-9343(02)01269-X.

66. Bednarek-Tupikowska G, Tupikowski K. Homocysteine - an underestimated atheromatosis risk factor. Do sex hormones influence homocysteine concentrations? [Homocysteina - niedoceniany czynnik ryzyka miażdżycy. Czy hormony płciowe wpływają na stężenie homocysteny? in Polish] Adv Hyg Exp Med. 2004;58:381-389.

67. Herrmann M, Obeid R, Scharhag J, Kindermann W, Herrmann W. Altered vitamin B12 status in recreational endurance athletes. Int J Sport Nutr Exerc Metab. 2005; 15(4):433-441;doi: 10.1123/ijsnem.15.4.433.

68. Malinov MR, Bostom AG, Krauss RM. Homocyst(e)ine, diet, and cardiovascular disease. A statement for healthcare professional from the Nutrition Committee, American Heart Association. Circulation. 1999;99(1):178-182; doi: 10.1161/01.CIR.99.1.178.

69. Nilsson K, Isaksson A, Gustafson L, Hultberg B. Clinical utility of serum holotranscobalamin as a marker of cobalamin status in elderly patients with neuropsychiatric symptoms. Clin Chem Lab Med. 2014;42(6): 637-643; doi: 10.1515/CCLM.2004.109.

70. Gargari BP, Aghamohammadi V, Aliasgharzadeh A. Effect of folic acid supplementation on biochemical indices in overweight and obese men with type 2 diabetes. Diabetes Res Clin Pract. 2011;94(1):33-38; doi: 10.1016/j.diabres.2011.07.003. 